\title{
Correction to: Introduction: the future of public space
}

\author{
Tigran Haas ${ }^{1} \cdot$ Michael W. Mehaffy ${ }^{2}$
}

Published online: 25 March 2019

(c) Springer Nature Limited 2019

\section{Correction to: URBAN DESIGN International https://doi.org/10.1057/s41289-018-0062-3}

The following paragraph on page 2 (bottom of first column) has been removed.

"Setha Low, in "Public space and diversity: Propositions for social justice in street, parks and plazas" argues that public spaces function as the most important forum for the development of a socially just society-the places where "race, class, gender, age, sexual preference, ethnicity and ability differences are experienced and negotiated in a forum for political action, communication, and democratic practice." What is needed is a set of shared tools and strategies to "improve urban public spaces that are being restricted and homogenized by neoliberal governance strategies." Professor Low is Director of the Public Space Research Group at City University of New York, and Professor of Anthropology, Sociology, and Environmental Psychology."

Publisher's Note Springer Nature remains neutral with regard to jurisdictional claims in published maps and institutional affiliations.

The online version of the original article can be found under doi: https://doi.org/10.1057/s41289-018-0062-3.

Tigran Haas

tigran.haas@abe.kth.se

1 Centre for the Future of Places (CFP), School of Architecture and the Built Environment, KTH, Stockholm, Sweden

2 Center for the Future of Places, KTH Royal Institute of Technology, Stockholm, Sweden 